\title{
The Missing Piece: Connecting SoTL and Student Learning
}

A Review of Faculty Development and Student Learning: Assessing the Connections

by William Condon, Ellen R. Iverson, Cathryn A. Manduca, Carol Rutz, and Gudrun Willett

\begin{abstract}
"It was missing a piece.
And it was not happy.

So it set off in search

of its missing piece."
\end{abstract}

Shel Silverstein, The Missing Piece

In The Missing Piece, children's author and illustrator Shel Silverstein (1976) tells the story of an incomplete circle that sets off on a journey to fill the gap it perceives in itself. A meandering adventure ensues, concluding with a lesson about what the circle learns when it finally finds what it had been seeking.

In the important new book Faculty Development and Student Learning (2016), William Condon, Ellen R. Iverson, Cathryn A. Manduca, Carol Rutz, and Gudrun Willett also tell the tale of a journey intended to fill a meaningful gap. At the heart of their quest is a simple question: "When faculty change their teaching, what is the impact on student learning?" (p. 92).

SoTL's inability to conclusively answer that question is a missing piece. A big one. Ample evidence demonstrates that SoTL changes teaching practices (Hutchings, Huber, \& Ciccone, 2011). That is significant, but SoTL's fundamental aim is enhanced student learning (Felten, 2013) and the evidence of SoTL's connection to student learning remains thin. As Keith Trigwell argued in the inaugural issue of this journal, "There is very little empirical evidence that the teachers who engage with SoTL ... are also improving their students' learning, or even teaching in a way that is associated with higher quality learning, yet this is clearly the purpose of" SoTL (2013, p. 97).

Like the Silverstein fable, the missing piece Condon and colleagues seek is "elusive" (Condon et al., p. 92). If it can be uncovered, however, the case for SoTL will be complete. As Richard Haswell writes in the book's afterword, what these authors find at the end of their journey "may startle a fair portion of the post-secondary world" (p. 131).

\section{THE TRACER STUDY}

The authors call the powerful study at the heart of this book "Tracer" because it aimed to trace connections from faculty development to teaching practices and then to student learning. Tracer, as Pat Hutchings describes in the foreword, "was conducted as a kind of SoTL inquiry itself... beginning with 'what works' questions but moving on to more fundamental inquiries about 'what's going on' and 'what's possible' in the future” (p.x). Because of this approach, Tracer is important to the SoTL community not only for its findings but also for its research design and methodologies. 
Tracer explored "the effects of faculty development into students' learning through course work products and, more generally, into the institutional culture that supports a teaching community" (p. 2). This mixed-methods study built on major faculty development initiatives focusing on broad and significant student outcomes: "writing, higher-order thinking, and quantitative reasoning" (p. 93). Tracer collected data linked to these programs including the following:

a. self-reported faculty perceptions of teaching,

b. direct observations of faculty teaching through both analysis of course materials (particularly assignments) and observations of teaching, and

c. student learning measured through analysis of student course work (p. 31).

Tracer took a longitudinal lens to its inquiry, recognizing that "the single [faculty development] workshop is not the correct unit of measure" to study faculty change (p. 58).

The study gathered this evidence from two very different US higher education institutions over three years. Washington State University is a large (25,000 students) public research university, while Carleton College is a much smaller (2,000 students) undergraduate-only private liberal arts institution. Despite the many distinctions between these institutions, Tracer concentrated on three common "sites" where faculty learn to improve their teaching:

1. Formal faculty development programming such as workshops and conferences,

2. “Intentional, self-directed efforts to examine and improve one's own teaching" such as SoTL inquiries conducted by individual faculty, and

3. "Routine events - annual reviews, hiring processes, departmental goal setting — that are by no means intended as sites for learning about teaching but that carry incidental opportunities to do so" (p. 5).

The book dives into Tracer's evidence in each of these sites. The authors uncover persuasive evidence at both Washington State and Carleton that all three sites of faculty development prompted faculty to make intentional changes in their teaching practices that resulted in enhanced student learning:

the greatest effects concern the aggregate impact of multiple professional development experiences and the varied interactions they generate among instructors on a campus. This study shows that these effects are large, extend beyond the participants in formal faculty development programs, and guide an institutional culture that supports reflective, scholarly teaching. This generative culture of teaching and learning provides a crucial environment for ongoing faculty learning that benefits students, faculty, and the institution as a whole. (p.6)

Condon and his colleagues offer practical advice for others who would like to conduct similar research (specifically, pp. 111-12 and 116-17). For instance, the authors conclude that the limits of their own study "highlight the need for longitudinal research on the same students" (p. 108). Two of Tracer's main lessons for SoTL scholars, however, reach beyond practical methodological issues to sketch "visions of the possible" for the field. First, finding evidence to connect student learning to faculty development "is difficult, but not impossible" (p. 111). Second, Tracer demonstrates "that disparate institutions can collaborate and learn from one another" (p. 13). Taken as a whole, Tracer's methods offer a model for future SoTL inquiries, and its success demonstrates the potential of multi-institutional SoTL initiatives. As the authors conclude, "Results of this research demonstrate the need for more, larger, and better studies of faculty learning as it affects student learning" (p. 44). 


\section{IMPLICATIONS OF TRACER'S FINDINGS FOR SOTL}

Besides being a model multi-institutional study and presenting powerful findings, Tracer points to at least two important issues that deserve additional attention from the SoTL community.

\section{Faculty working conditions influence teaching and learning}

At both institutions in the Tracer study, researchers found significant links between faculty contract status and student learning. Contingent and new faculty at Washington State and Carleton actively engaged in faculty development, but often from a "defensive" stance that made them hesitant to try new teaching approaches for fear of negative student evaluations. This meant that, perhaps counterintuitively, tenured long-term faculty at these two research-intensive institutions were more innovative and effective teachers than their peers whose appointments focused primarily or exclusively on teaching (p.67). In Tracer, the "differentials in outcomes can be attributed more to conditions of employment than to initial qualifications or subsequent teaching experience” (p. 101). This leads to a troubling conclusion: "Clearly, greater appointment security—whether tenure-track lines or longer continuing appointments — result in higher learning for students” (p. 102)

Issues around faculty working conditions have received relatively little attention in the SoTL literature, although informal conversations at conferences suggest that many of us may have concerns about these conditions on our own campuses. The Tracer study suggests the value of using SoTL's tools to investigate the relationships between faculty working conditions and student learning.

\section{The focus of an inquiry influences perceptions of its importance}

Tracer's research focused on institution-wide and well-funded faculty development initiatives on critical thinking (Washington State), qualitative reasoning (Carleton), and writing across the curriculum (both institutions). The scale of these programs allowed the Tracer to generate broad and deep evidence of both faculty and student learning. These programs also "sprang from faculty values and interests" ( $p$. 26), ensuring wide participation on both campuses.

Analyzing the interview and other data from Tracer, the researchers conclude that these faculty development initiatives might have been particularly successful in yielding pedagogical change because so many faculty found the topics significant to their own teaching, regardless of discipline. The authors claim that faculty development programs typically shy away from complex topics like critical thinking or quantitative reasoning in favor of smaller, more practical themes such as course design or discussionleading. This choice, however, has consequences: "Targeting simpler outcomes provides a clear focus for development, but it also carries the message that this development is not really very important-thus making success more difficult to attain" (p. 120).

Might SoTL suffer from a similar tension between big and small targets of inquiry? SoTL studies often are modest explorations of highly contextual aspects of learning (Bernstein, 2010). While this approach allows for manageable and ethical studies, it also may unintentionally contribute to perceptions that SoTL is not valuable or important. If SoTL scholars only ask small questions about very particular aspects of learning, what do we have to offer our colleagues, disciplines, and institutions? Perhaps Tracer should embolden some in SoTL to address larger questions that can only be pursued with mixed-methods, longitudinal data, and multi-institutional collaboration.

\section{THE MISSING PIECE}

The depth of the Tracer study allows the authors to challenge a pervasive assumption in US higher education: "everyone 'knows' that faculty don't care about teaching” (p. 4). Although both 
Washington State and Carleton emphasize research in the formal processes used to evaluate faculty performance, at each institution the Tracer team struggled to identify faculty who did not participate in at least some faculty development activities related to teaching (p. 62). Indeed, across the two institutions, "Faculty see teaching as engaging in a process of continual learning and improvement" ( $p$. 64). This orientation may not lead to participation in official faculty development programming, but it means that many faculty work diligently, if quietly, to improve their own teaching and to enhance their students' learning. That finding, which is the claim that Richard Haswell notes, may "startle" many in higher education, leads the authors to a powerful conclusion: "what many perceive as a failing of individual faculty to value teaching may in fact reflect the absence of a culture that supports teaching and learning" (p. 126).

Tracer suggests that a teaching-positive culture is the missing piece on many campuses: "A generative culture multiplies the impact of formal faculty development, enhances self-motivated, individual faculty learning, and supports faculty experimentation in their courses" (p. 121). The authors, unfortunately, do not draw on excellent scholarship from outside the United States about this topic (or other topics); they cite one valuable US-based study on faculty culture (Beyer, Taylor, \& Gillmore, 2013), but they fail to build on influential work from scholars in other countries who have explored to this issue (such as Roxa \& Martensson, 2009, and Kreber, 2013).

Despite the international gap, the end of the Tracer journey echoes Silverstein's fable because we discover that we already have what we are seeking. One of the core features of SoTL is an orientation toward teaching and learning that has the potential to contribute to both individual and institutional change. As Dan Bernstein has argued in this journal, "While being active in the Scholarship of Teaching and Learning has clear and significant benefits for the individuals participating, we should not underestimate or ignore the benefits of SoTL activity for the institutions in which those faculty members work" (2013, p. 35). The Tracer study not only offers new insights into learning, teaching, faculty development, and SoTL, but it also reminds us of the importance of using our own inquiries to cultivate the "generative culture" that enables all faculty, including those who do not participate in SoTL, to systematically enhance teaching so that all of our students learn more deeply.

Peter Felten is assistant provost for teaching and learning, executive director of the Center for Engaged Learning, and professor of history at Elon University. He is president (2016-2017) of the International Society for the Scholarship of Teaching and Learning.

\section{REFERENCES}

Bernstein, D. (2010). Finding your place in the scholarship of teaching and learning. International Journal for the Scholarship of Teaching and Learning, 4. DOI http://dx.doi.org/10.20429/ijsotl.2010.040204

Bernstein, D. (2013). How SoTL-active faculty members can be cosmopolitan assets to an institution. Teaching \& Learning Inquiry, 1, 35-40. DOI: http://dx.doi.org/10.20343/teachlearninqu.1.1.35

Beyer, C., Taylor, E., \& Gillmore, G. (2013). Inside the undergraduate teaching experience: The University of Washington's growth in faculty teaching study. Albany: State University of New York Press.

Condon, W., Iverson, E. R., Manduca, C. A., Rutz, C., \& Willett, G. (2016). Faculty development and student learning: Assessing the connections. Bloomington: Indiana University Press.

Felten, P. (2013). Principles of good practice in SoTL. Teaching \& Learning Inquiry, 1, 121-125. DOI: http://dx.doi.org/10.20343/teachlearninqu.1.1.121

Hutchings, P., Huber, M. T., \& Ciccone, A. (2011). The Scholarship of teaching and learning reconsidered: Institutional integration and impact. San Francisco: Jossey-Bass.

Kreber, C. The transformative potential of the scholarship of teaching and learning. Teaching \& Learning Inquiry, 1, 5-18. DOI: http://dx.doi.org/10.20343/teachlearninqu.1.1.5 
Roxå, T., \& Mårtensson, K. (2009). Significant conversations and significant networks: Exploring the backstage of the teaching arena. Studies in Higher Education, 34, 547-559. DOI: 10.1080/03075070802597200

Silverstein, S. (1976). The Missing piece. New York: Evil Eye Music.

Trigwell, K. (2013). Evidence of the impact of scholarship of teaching and learning purposes. Teaching \& Learning Inquiry, 1, 95-105. DOI: http://dx.doi.org/10.20343/teachlearninqu.1.1.95

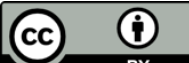

Copyright for the content of articles published in Teaching \& Learning Inquiry resides with the authors, and copyright for the publication layout resides with the journal. These copyright holders have agreed that this article should be available on open access under a Creative Commons Attribution License 4.0 International (https://creativecommons.org/licenses/by/4.0). The only constraint on reproduction and distribution, and the only role for copyright in this domain, should be to give authors control over the integrity of their work and the right to be properly acknowledged and cited, and to cite Teaching \& Learning Inquiry as the original place of publication. Readers are free to share these materials-as long as appropriate credit is given, a link to the license is provided, and any changes are indicated. 